\title{
SEMEN OF THE CEYLON ELEPHANT, ELEPHAS MAXIMUS
}

\author{
M. R. JAINUDEEN, J. F. EISENBERG AND J. B. JAYASINGHE \\ Faculty of Veterinary Science, University of Ceylon, Peradeniya, Ceylon, and \\ National Zoological Park-Smithsonian Institution, Washington D.C., U.S.A.
}

\section{(Received 23rd March 1970)}

Summary. The procedure employed for the collection of semen from a captive male elephant is described. Sperm-rich and sperm-free ejaculates were obtained. Seven sperm-rich ejaculates were evaluated.

Seminal characteristics investigated in the elephant compared favourably with those of other domestic animals of normal fertility. The mean concentration of spermatozoa was $1200 \times 10^{6} / \mathrm{ml}$ in the sperm-rich ejaculates. Individual spermatozoa measured $58.5 \mu$ (average) in length.

\section{INTRODUCTION}

Assessment of semen quality to determine the potential fertility of breeding sires is performed routinely amongst domestic animals. In Ceylon, a programme has been undertaken to breed elephants in captivity, but selecting sires is difficult as none of the males has previously sired any calves under these conditions. It appeared that studies of the semen characteristics of captive elephants might be of value in selecting sires for the breeding programme.

The anatomy of the male reproductive organs has been described in detail for the Indian elephant, Elephas maximus (Schulte, 1937), and for the African elephant, Loxodonta africana (Johnson \& Buss, 1967; Short, Mann \& Hay, 1967), but only a few observations pertain to semen. Landowski \& Gill (1964) studied the semen of a Ceylon elephant (E. maximus) collected from the vagina immediately after copulation.

The present report is based on the microscopical methods employed to assess semen quality in the Ceylon elephant, Elephas maximus.

\section{MATERIALS AND METHODS}

\section{Experimental animal}

In September 1969, a unique and an unexpected opportunity occurred to study semen characteristics in a 35-year-old captive elephant. The animal was unable to mount females in oestrus due to difficulties in bearing weight on its hind feet. It was, therefore, necessary to devise a method of collecting semen to transfer it into the female tract by mechanical means. 


\section{Method of collection}

A close relationship exists between captive elephants and their keepers in Geylon. It is well known that a male elephant will protrude its penis from the sheath when its keeper 'speaks' to the animal and gently strokes the pectoral region. This procedure was slightly modified to collect semen samples. The male was allowed access to a female in oestrus for a period of 30 to $45 \mathrm{~min}$ ( $\mathrm{Pl}$. 1, Fig. 1). When the male made attempts to mount, it was separated from the female and time was allowed for the penis to retract into the sheath. The keeper then 'spoke' to and gently stroked the male and within a few seconds, the penis was protruded and fluid flowed immediately (Pl. 1, Fig. 2).

The term 'ejaculate' used in this study refers to the fluid resulting from such stimulation. The ejaculate was collected into a clean 500-ml glass beaker.

\section{Semen evaluation}

Ejaculate volume, colour and density were recorded. Wave pattern, gross motility and the \% spermatozoa showing progressive forward motility were assessed immediately. The $\mathrm{pH}$ was determined electrochemically using a Pye Universal $\mathrm{pH}$ meter. Eosin-nigrosin smears were prepared (Campbell, Dott $\&$ Glover, 1956). One hundred spermatozoa were counted per smear at a magnification of $\times 400$ and classified as stained (dead) or unstained (live) together with the estimates of abnormal forms of spermatozoa. A total of 100 spermatozoa were measured with a previously calibrated micrometer eyepiece under oil immersion in four smears stained with eosin-nigrosin. Sperm concentration was determined with the aid of a haemocytometer.

\section{RESULTS}

\section{Ejaculate}

Two types of ejaculates were obtained by this procedure. The first was a sperm-free, viscid, gelatinous material of egg-white consistency, 50 to $75 \mathrm{ml}$ in quantity and contained a few dead spermatozoa (four ejaculates). The second type of ejaculate was a sperm-rich, greyish-white, watery fluid, 5 to $25 \mathrm{ml}$ in volume, and contained a high concentration of motile spermatozoa (seven ejaculates).

\section{Seminal characteristics}

Table 1 summarizes the seminal characteristics of seven sperm-rich ejaculates. In the undiluted ejaculate, distinct wave patterns were observed at low magnification $(\times 100)$. Spermatozoa exhibited several types of motility which included progressive forward movement, circling and oscillatory activity. Approximately $50 \%$ of the motile cells exhibited the progressive type of motility immediately after collection, but the numbers decreased with time as a result of head-to-head clumping of motile spermatozoa (Pl. 1, Fig. 3). Such clumped spermatozoa were viable for a longer period that those that were moving freely. Sperm motility in the sperm-rich ejaculates improved with the addition of previously obtained sperm-free ejaculates.

In preparations stained with eosin and nigrosin, the majority of sperm heads 
PI.XTl: 1

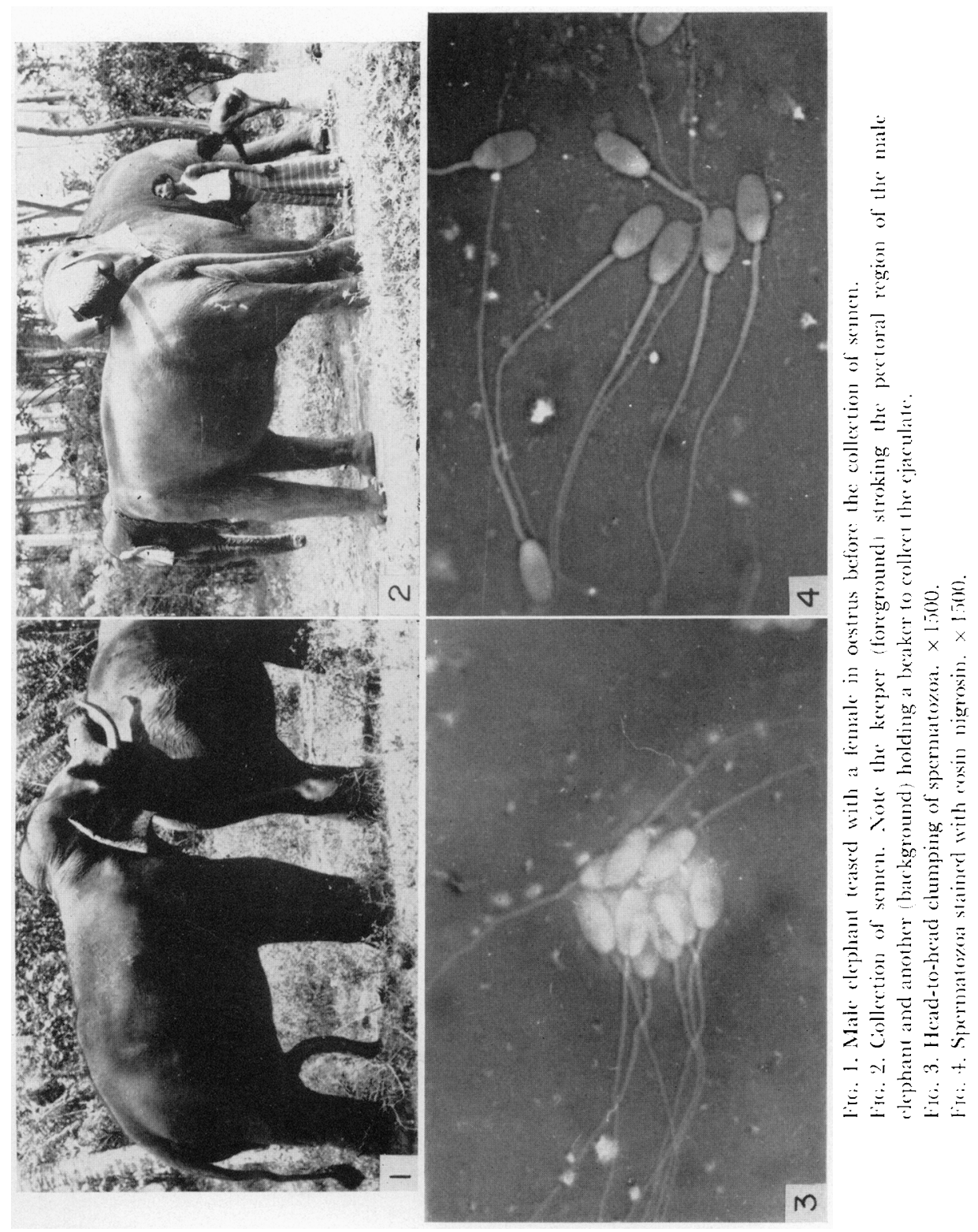

Lacing f, 2) $1+$ 
took on a slight pink colour. Abnormal cells observed included loose normal heads and tails that were bent or coiled.

Size of spermatozoa

Table 2 summarizes the measurements of 100 spermatozoa of the Ceylon elephant. All the spermatozoa analysed had constant measurements for the head and mid-piece. The only variation observed was in the length of the mainpiece $(37.5$ to $43.5 \mu)$. The mid-piece was only slightly thicker than the mainpiece (Pl. 1, Fig. 4).

TABLE 1

SEMINAL GHARACTERISTICS OF THE ELEPHANT*

\begin{tabular}{l|c|c}
\hline \multicolumn{1}{c|}{ Characteristic } & Mean & Range \\
\hline Ejaculate volume (ml) & 9 & 5 to 25 \\
pH of semen & $8 \cdot 1$ & 8 to $8 \cdot 4$ \\
Spermatozoa & & \\
Progressive motility (\%) & 50 & 40 to 70 \\
Concentration $\left(10^{6} / \mathrm{ml}\right)$ & 1200 & 600 to 2000 \\
Live $(\%)$ & 83 & 62 to 90 \\
Abnormal (\%) & 16 & 10 to 21 \\
& & \\
\hline
\end{tabular}

* Based on seven sperm-rich ejaculates.

TABLE 2

A COMPARISON OF THE DIMENSIONS OF SPERMATOZOA OF Elephas maximus* AND Loxodonta africana $\dagger$

\begin{tabular}{l|c|c}
\hline & E. maximus* & L. africana $\dagger$ \\
\hline Head & 7.5 & 6 \\
Length $(\mu)$ & 4.5 & 2.5 to 3 \\
Width $(\mu)$ & 10.5 & 8.6 \\
Mid-piece $(\mu)$ & 40.5 & 47 \\
Main-piece $(\mu)$ & & \\
\hline
\end{tabular}

* Present study.

$\dagger$ Johnson \& Buss (1967).

\section{DISCUSSION}

The underlying mechanism whereby ejaculation is initiated by the procedure employed in this study needs further investigation. The present success may merely reflect the ability of an individual elephant to respond to the chosen stimulus. There is also no obvious explanation for the two types of ejaculates obtained. Under conditions of mating the elephants in captivity, we have observed a copious secretion of a stringy transparent fluid from the erect penis immediately before intromission. It is, therefore, likely that the ejaculate consists of at least two fractions-an initial, voluminous, sperm-free fraction followed 
by a smaller sperm-rich fraction. When these fractions were combined, the concentration of spermatozoa in the semen was low and similar to the values observed in species that ejaculate a large volume of semen, such as the stallion or the boar (Mann, 1959). Previously reported concentrations of 50 to $700 \times 10^{6}$ spermatozoa/ml in elephant semen (Landowski \& Gill, 1964) are lower than those in our study, probably because the sperm-rich fraction was diluted with the sperm-free fraction and vaginal secretions. There is, however, a close agreement in $\mathrm{pH}$ values for elephant semen.

The seminal characteristics of the elephant in this study compare very favourably with those of other domestic animals of normal fertility. However, in the absence of previous data on the ability of the animal to sire calves, no definite conclusions on the fertility of this animal could be drawn at present. Our observations that sperm motility could be improved by the addition of spermfree ejaculates confirm those of Short et al. (1967), who reported that the motility of spermatozoa obtained from the mesonephric duct improved with the addition of vesicular secretions. The phenomenon of head-to-head clumping of elephant spermatozoa (Landowski \& Gill, 1964) was also observed in our study. Since this phenomenon increased with continuous examination of the sample, it is probably a secondary abnormality related to such adverse influences as temperature, light and handling of samples after collection.

The measurements of the spermatozoa of E. maximus shown in Table 2, are identical with those reported by Landowski \& Gill (1964). According to Schulte (1937), the dimensions of the spermatozoon of the Indian elephant, $E$. maximus, were reported for the 'body' length as $8 \cdot 3 \mu$ and for the 'tail' as equal to five times this value, $41.5 \mu$. The term 'body' in his description probably referred to the head-piece, while the 'tail' included both the mid-piece and mainpiece. Thus the total length of a spermatozoon, as measured by Schulte, would be approximately $49 \cdot 8 \mu$. This length is about $20 \%$ smaller than the size of a spermatozoon in our study $(58.5 \mu)$. In Table 2, a comparison is made of the sperm measurements of E. maximus and L. africana (Johnson \& Buss, 1967). The spermatozoon of the Geylon elephant is only slightly shorter in length, but both the head-piece and mid-piece are longer than in the African elephant.

The phenomenon of 'musth' in relation to reproduction in the elephant remains uncertain. In African elephants, musth is observed in both sexes and all ages (Perry, 1953), but in captive elephants in Ceylon it is restricted to males over 20 years of age (Jainudeen \& Eisenberg, unpublished data). In captive elephants, musth is 1 to 3 months in duration and is characterized by (1) aggressive behaviour, (2) profuse secretion from the temporal glands, (3) continuous dribbling of urine from the preputial orifice, and (4) an inability to protrude the penis from the sheath to effect erection. The male used in this study was not in musth and showed frequent erection of the penis (see Pl. 1, Fig. 1). Further, during the 3 to 4 days of oestrus, no female showed a discharge from the temporal glands. Thus, there is little justification for assuming that reproductive mechanisms, at least in captive elephants, are dependent on musth.

From a practical point of view, collection of semen opens enormous possibilities for elephant breeding in captivity on a large scale. If semen could be col- 
lected regularly from a few proven sires, it might then be possible to inseminate captive female elephants by artificial means and thereby reduce the chances of injury to the female during natural mating.

\section{AGKNOWLEDGMENTS}

This work was supported by a Smithsonian Institution grant to one of us (J.F.E.). We would like to thank $\mathrm{Dr} \mathrm{N}$. Tilakeratne for the supervision of the breeding project and Dr L. A. P. Britto-Babapulle, Jr for taking photomicrographs.

\section{REFERENCES}

Campeel. , R. C., Dotт, H. M. \& Glover, T. D. (1956) Nigrosin-eosin as a stain for differentiating live and dead spermatozoa. 7. agric. Sci., Camb. 48, 1.

Jorinson, O. W. \& Buss, I. O. (1967) The testis of the African elephant (Loxodonta africana). I. Histological features. J. Reprod. Fert. 13, 11.

Landowski, J. \& GiLl, J. (1964) Einige Beobachtungen über das Sperma des Indischen Elefanten (Elephas maximus L.). Zool. Gart., Lpz, 29, 15.

MANN, T. (1959) Biochemistry of semen and secretion of male accesory organs. In: Reproduction in Domestic Animals, Vol. II. Eds. H. H. Cole and P. T. Cupps. Academic Press, London.

Perry, J. S. (1953) The reproduction of the African elephant, Loxodonta africana. Phil. Trans. R. Soc. B, $237,93$.

Schulte, T. L. (1937) The genito-urinary system of the Elephas indicus male. Am. 7. Anat. 61, 131.

Short, R. V., ManN, T. \& HAY, M. F. (1967) Male reproductive organs of the African elephant, Loxodonta africana. 7. Reprod. Fert. 13, 517. 